\title{
Estimation of Tracer Diffusion Coefficients of Ions in Aqueous Solution
}

\author{
Donald G. Miller
}

Manuscript date: September 7, 1982

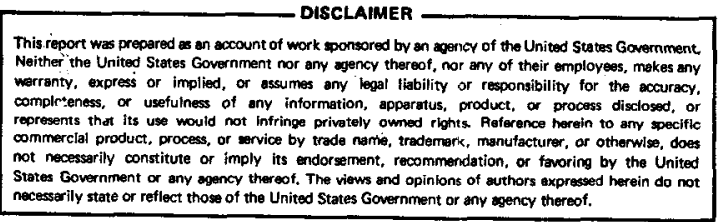

\section{LAWRENCE LIVERMORE LABORATORY University of California $\bullet$ Livermore, California $\bullet 94550$}




\section{DISCLAIMER}

This report was prepared as an account of work sponsored by an agency of the United States Government. Neither the United States Government nor any agency Thereof, nor any of their employees, makes any warranty, express or implied, or assumes any legal liability or responsibility for the accuracy, completeness, or usefulness of any information, apparatus, product, or process disclosed, or represents that its use would not infringe privately owned rights. Reference herein to any specific commercial product, process, or service by trade name, trademark, manufacturer, or otherwise does not necessarily constitute or imply its endorsement, recommendation, or favoring by the United States Government or any agency thereof. The views and opinions of authors expressed herein do not necessarily state or reflect those of the United States Government or any agency thereof. 


\section{DISCLAIMER}

Portions of this document may be illegible in electronic image products. Images are produced from the best available original document. 


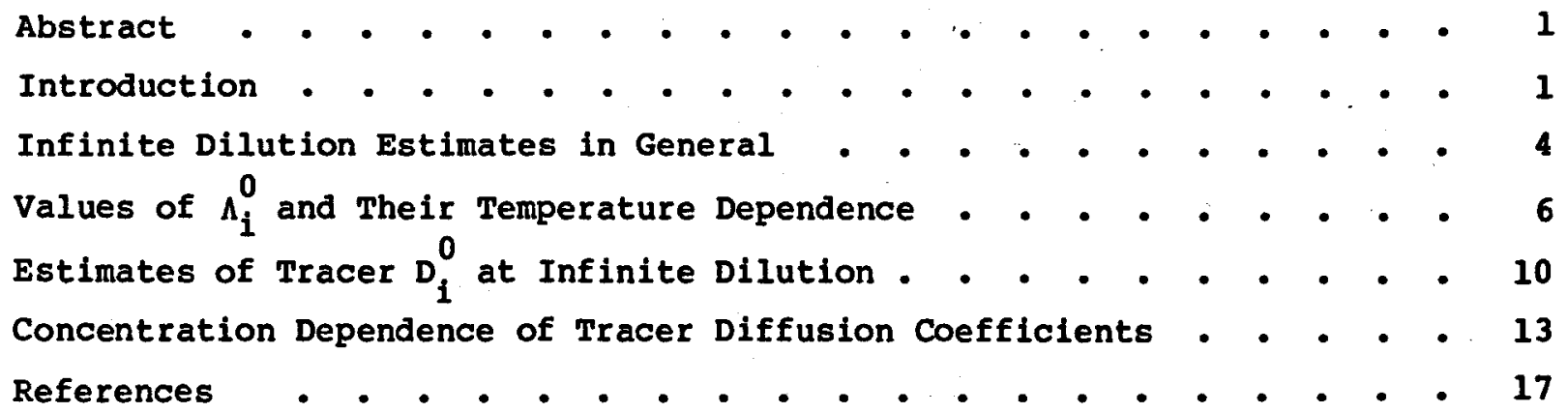


ABSTRACT

Equations are given for estimating tracer diffusion coefficients $D_{i}^{0}$ of ions at infinite dilution in terms of limiting ionic conductances $\Lambda_{i}^{0}$. Also given are generalized Nernst-Hartley equations for binary and multicomponent diffusion coefficients $D^{0}$ and $D_{i j^{\prime}}^{0}$ respectively, at infinite dilution. Data, estimates, and correlations for $\Lambda_{i}^{0}$ at $25^{\circ} \mathrm{C}$ and other temperatures are discussed. Estimated values of $\Lambda_{i}^{0}$ are tabulated from $0-300^{\circ} \mathrm{C}$ for ions of waste isolation interest and for lons of economic interest in geothermal brines. Estimates of their tracer diffusion coefficients at infinite dilution are tabulated. A rule of thumb, good to a factor of 2, is presented. Very limited data (available only at $25^{\circ} \mathrm{C}$ ) indicate that $D_{i} / D_{i}^{0}$ generally declines as the concentration of salt or supporting electrolyte increases.

INTRODUCTION

Transport data are frequently required to accurately model systems of practical interest. Examples are the precipitation of valuable metals from geothermal brines, the diffusive transport of radioactive isotopes away from a flooded repository, the diffusion of salt between the two aqueous layers of a solar pond, the diffusion to and from electrodes in battery systems, etc. clearly, diffusion coefficients are an important transport property. 
Diffusion is complex, since $n^{2}$ diffusion coefficients are required for $n$ solutes in a solvent. Fortunately tracer diffusion, useful in some applications, is simpler. Unfortunately diffusion coefficients are difficult to measure even in 1-solute systems, and there are little data--especially at temperatures greater than $25^{\circ} \mathrm{C}$. There are much less data in multicomponent systems; there is nothing at higher temperatures except a few tracer results, and the experiments are much more difficult.

It is thus desirable to find ways of estimating diffusion coefficients in binary and multicomponent systems. Unfortunately the concentration dependences of binary systems are too complex to predict in advance, especially for electrolytes. Figure 1 shows examples of this complexity. Moreover, there are not enough systematic data for multicomponent systems to see- whether binary data can be successfully used to predict multicomponent properties. There is a method based on irreversible thermodynamics which does work well for $1-1$ strong electrolyte mixtures, ${ }^{1}$ but which requires extensive binary transport data. However, for higher valence type mixtures, this method has not yet been tested.

For very dilute electrolyte solutions, however, it is possible to make estimates of the diffusion coefficients by generalizing the old Nernst-Hartley equation. The equations ${ }^{1}$ are given below [Eq. (3)], and are valid at all concentration ratios. The data required are just the limiting ionic conductances (infinite dilution values) $\Lambda_{i}^{0}$ as a function of temperature. In this report, we shall be concerned with estimates of tracer diffusion coefficients at various temperatures, with emphasis on ions with economic value from geothermal brines and on ions of radioactive isotopes. As noted earlier, there are few real data to use as guidance for tracer diffusion 


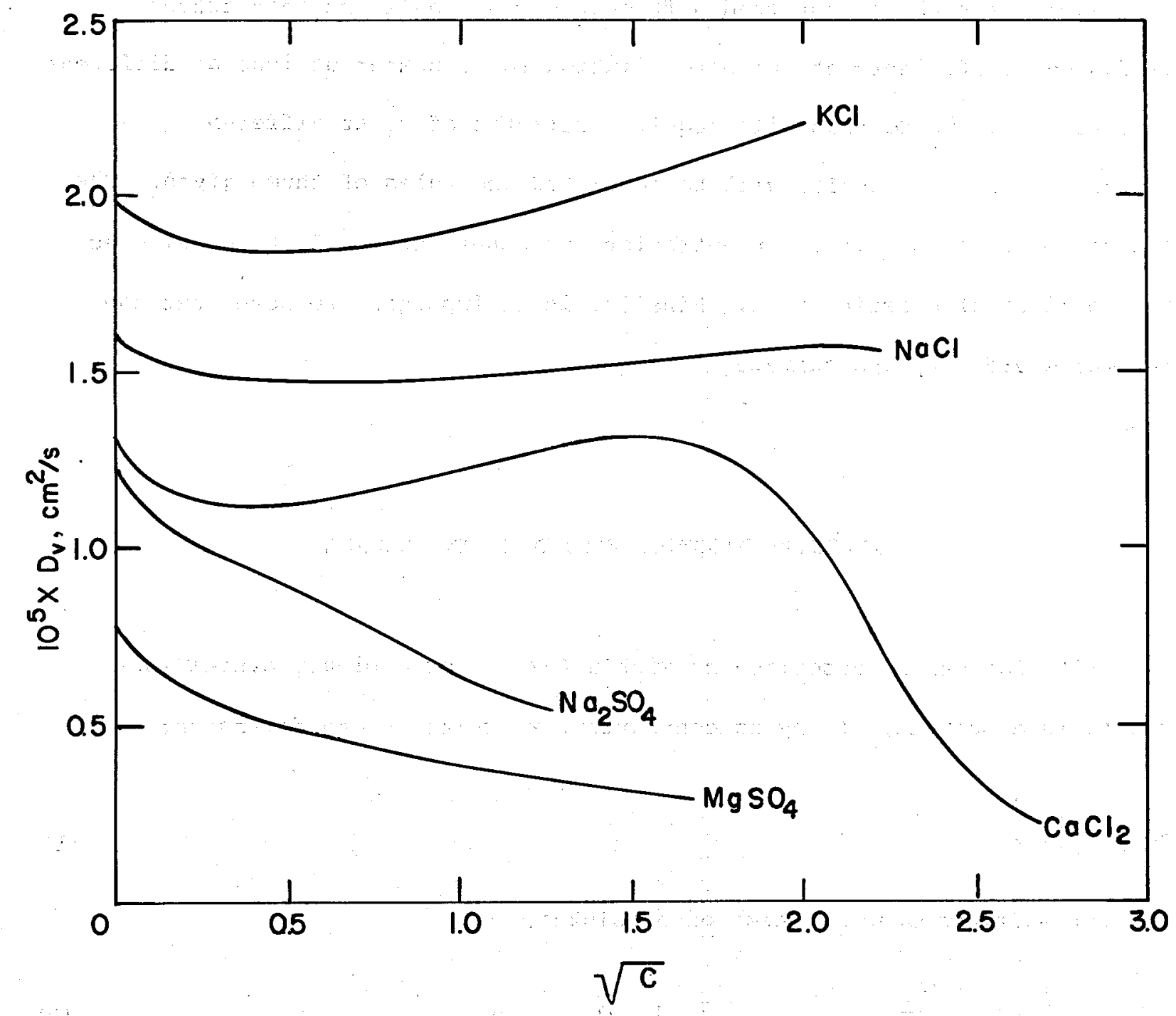

Figure 1. Concentration dependence of diffusion coefficients at $25^{\circ} \mathrm{C}$ for some electrolytes found in brines, seawater, and ground waters.

coefficients $D_{i}$ in the high concentrations of other salts associated with either brines or salt beds. There are also few data for $\Lambda_{i}^{0}$ at higher temperatures for infinite dilution estimates. Moreover, the complex-forming transition metals like $\mathrm{Zn}, \mathrm{Ca}$, and Fe are not strong electrolytes. Our expectation is that $D_{i}$ will be lower for a charged complex ion. Finally, Nernst-Hartley-type equations themselves are poor approximations at finite concentrations. 
Despite the above-mentioned difficulties, we shall estimate tracer diffusion coefficients at infinite dilution for a number of ions at different temperatures. To do this will require estimates of $\Lambda_{i}^{0}$ at different temperatures. The results will be tabulated and rules of thumb given: The effects on $D_{i}$ from higher concentrations of other salts will be considered in the light of existing data. Finally, it is important to note that the estimates are very approximate.

INFINITE DILUTION ESTIMATES IN GENERAL

Diffusion can be described by Fick's Law. ${ }^{2}$ For a binary system (one solute in a solvent) of any concentration, we write in one dimension:

$-J=D \frac{\partial C}{\partial x}$

and for multicomponent systems of $n$ solutes:

$$
-J_{i}=\sum_{j=1}^{n} D_{i j} \frac{\partial c_{i}}{\partial x}, \quad i=1, \ldots, n
$$

where $J, J_{i}$ are flows; $D, D_{i j}$ are diffusion coefficients $\left(\mathrm{cm}^{2} / \mathrm{s}\right) ; \mathrm{C}$, $c_{i}$ are volume concentrations in $\mathrm{mol} / \mathrm{dm}^{3}$, and $x$ is the distance. By writing out Eq. (2), it is clear that a 2-solute system requires 4 diffusion coefficients and a 3-solute system requires 9, etc. Sometimes the cross terms $i \neq j$ are quite large (and even negative), and can exceed a main term coefficient $D_{i i} \cdot^{3}$

For infinite dilution in electrolyte solutions which have a common anion (characteristic of brines and many natural waters), the generalizations of the Nernst-Hartley equation can be derived from irreversible thermodynamics. 1,4 
These equations are presented for convenience if more than tracer results are wanted:

Binary:

$D^{0}=\frac{R T}{F^{2}} \cdot \frac{\Lambda_{1}^{0} \Lambda_{n}^{0}}{\Lambda^{0}}\left(\frac{1}{z_{1}}-\frac{1}{z_{n}}\right)$

Mul ticomponent:

$D_{i j}^{0}=\frac{r_{j a}}{r_{i a}} \cdot \frac{\Lambda_{i}^{0}}{\Lambda^{0}} \frac{R T}{F^{2}}\left[\frac{\delta_{i j} \Lambda^{0}}{z_{i}}-x_{i}\left(\frac{\Lambda_{j}^{0}}{z_{j}}+\frac{\Lambda_{n}^{0}}{z_{n}}\right)\right] \quad i, j=1, \ldots, n-1$

where

$\Lambda^{0}=\sum_{i=1}^{n} x_{i} \Lambda_{i}^{0}$,

and where $n$ refers to the common anion, $i$ (up to $n-1$ ) refers to the various cations, $r_{i a}$ is the stoichiometric coefficient of ionization for the common anion of the ith salt whose formula is $C_{r_{i c}}{ }_{r_{i a}}, \Lambda_{i}^{0}$ is the limiting conductance of ion $i, R$ is the gas constant $(8.3144$ joules/mol $K), T$ is the absolute temperature in $K, F$ is the Faraday $\left(96,493\right.$ coulombs/equiv), $\delta_{i j}$ is the Kronecker delta, and $z_{i}$ is the valence of ion $i$ with due regard to sign. The equivalent fraction $x_{i}$ is given by

$x_{i}=\frac{N_{i}}{N}$

where

$N_{i}=r_{i c}{ }_{i} c_{i} \quad i=1, \ldots, n-1$

and

$N=\sum_{i=1}^{n-1} N_{i}$

where $r_{i c}$ is the stoichiometric coefficient of cation $i$, and $c_{i}$ is the concentration of salt $i$. The $D_{i j}$ correspond to the flows of salts, not ions. The superscript 0 refers to infinite dilution. 
It is easy to show from Eq. (3) that when salt $i$ (i.e., cation i) is present in trace amounts $\left(i . e ., c_{i} \cong 0\right), D_{i j}=0$ for $j \neq i$ and the tracer diffusion coefficient $D_{i}^{0}$ is given by $D_{i}^{0}=D_{i i}^{0}=\frac{R T \Lambda_{i}^{0}}{z_{i} F^{2}} . \quad$ (trace amount of $\left.i\right)$

A similar analysis for a tracer anion in any mixture leads to the same type of result:

$D_{k}^{0}=\frac{R T A_{k}^{0}}{\left|z_{k}\right| F^{2}} \cdot \quad$ (trace amount of $k$ )

Although we are not concerned with nonelectrolytes, the valuable book by Reid, Sherwood, and Prausnitz ${ }^{5}$ contains some estimation procedures for nonelectrolyte diffusion coefficients.

Equations (3a), (3b), (8), and (9) are very convenient for infinite dilution estimates since only $T$ and $\Lambda_{i}^{0}$ as a function of $T$ are required to estimate $D_{i}$ and $D_{i j}$.

VALUES OF $\Lambda_{i}^{0}$ AND THEIR TEMPERATURE DEPENDENCE

Data for a number of ions at $25^{\circ} \mathrm{C}$ are tabulated in Robinson and Stokes ${ }^{6}$ and Harned and $0{ }^{7}{ }^{7}$, with a few data listed between $0^{\circ}$ and $100^{\circ} \mathrm{C} .^{6}$ There are also $\Lambda_{i}^{0}$ data for a few ions at 200 and $300^{\circ} \mathrm{C}$ given by Quist and Marshall ${ }^{8}\left(\mathrm{H}^{+}, \mathrm{Li}^{+}, \mathrm{Na}^{+}, \mathrm{K}^{+}, \mathrm{NH}_{4}^{+}, \mathrm{OH}^{-}, \mathrm{Cl}^{-}, \mathrm{ESO}_{4}^{-}, \mathrm{SO}_{4}^{-2}\right)$, and data for $\Lambda^{0}$ of $\mathrm{NaCl}$ to $800^{\circ} \mathrm{C}$ by the same authors. 9

For ions not tabulated at $25^{\circ} \mathrm{C}$, estimates must be made by chemical analogy to similar ions which have been tabulated. For the ones which are tabulated at $25^{\circ} \mathrm{C}$ (but not at some or all of the other temperatures), 
estimates may be made by assuming the ionic conductances are parallel to or in between other ions whose $\Lambda_{i}^{0}$ are close at $25^{\circ} \mathrm{C}$ and when possible are chemically similar. Thus $\mathrm{Sr}^{+2}$ is assumed to be similar to $\mathrm{Ca}^{+2}$, and the value at $50^{\circ} \mathrm{C}$ is interpolated from a graph of $\mathrm{Ca}^{+2}$ data. In addition, values for $\mathrm{Cs}^{+}$and $\mathrm{I}^{-}$at $50^{\circ} \mathrm{C}$ are averages of 45 and $55^{\circ} \mathrm{C}$ data in Ref. 6 ; the error will be not more than 1-28.

Figure 2 shows plots of some data of Quist and Marshall 8,9 and Robinson and Stokes, ${ }^{6}$ plus some extrapolations for $\mathrm{Ba}^{+2}$ and $\mathrm{Ag}^{+}$to $300^{\circ} \mathrm{C}$ which follow the general curvature of the other ions. The $\Lambda_{i}^{0}$ for brine ions have been treated as follows: $\mathrm{Zn}^{+2}$ about 58 more than $\mathrm{Na}^{+} ; \mathrm{Cu}^{+2}$ as 0.94 of the average between $\mathrm{Na}^{+}$and $\mathrm{Ba}^{+2} ; \mathrm{Fe}^{+2}$ about 2.58 more than $\mathrm{Ca}^{+2} ; \mathrm{Pb}^{+2}$ as an average between $\mathrm{Ba}^{+2}$ and $\mathrm{Cl}^{-}$. Waste isolation ions have been treated as follows: $\mathrm{Cs}^{+}$like $\mathrm{Cl}^{-} ; \mathrm{T}^{+}$like $\mathrm{H}^{+} ; \mathrm{Sr}^{+2}$ about 78 less than $\mathrm{Ba}^{+2}$; $\mathrm{Ra}^{+2}$ about 28 more than $\mathrm{Ba}^{+2}$, assuming that $\Lambda_{\mathrm{Ra}}^{0}$ at $25^{\circ}$ is approximately 65 ; $\mathrm{Ce}^{+3}$ to be like $\mathrm{La}^{+3}$, and $\mathrm{La}^{+3}$ to be parallel to $\mathrm{Ba}^{+2}$ since $\Lambda_{100^{\prime}} \Lambda_{25} \cong 3.08$ \pm 0.04 for $\mathrm{La}^{+3}, \mathrm{Mg}^{+2}, \mathrm{Ca}^{+2}$, and $\mathrm{Ba}^{+2}$ (thus $\mathrm{Ce}^{+3}$ is about 9.78 more than $\mathrm{Ba}^{+2}$ ): $\mathrm{Pu}^{+3}$ like the rare earths with $\Lambda_{i}^{0}=64$ and otherwise the same as $\mathrm{Ba}^{+2} ; \mathrm{I}^{-}$like $\mathrm{Cl}^{-}$; and $\mathrm{TcO}_{4}^{-}$like $\mathrm{ReO}_{4}^{-}$at $25^{\circ} \mathrm{C}$ and about 7.58 more than $\mathrm{HSO}_{4}^{-}$at other temperatures.

These estimates are collected in Table 1 .

Alternate methods for estimating $\Lambda_{i}^{0}$ at $25^{\circ} \mathrm{C}$ have been described in an excellent paper by Nigrini. 10 He suggests correlations with 3 rd Law ionic entropies, entropies of hydration, or charge-to-radius ratios. Using the data base of Refs. 6-9, he obtains good results for cations in terms of charge-to-radius ratios. Unfortunately, however, anions do not correlate well with any of his suggested quantities. The uncertaintles in $\AA_{i}^{0}$ from estimating cation radii are about the same as from our use of chemical similarity. 


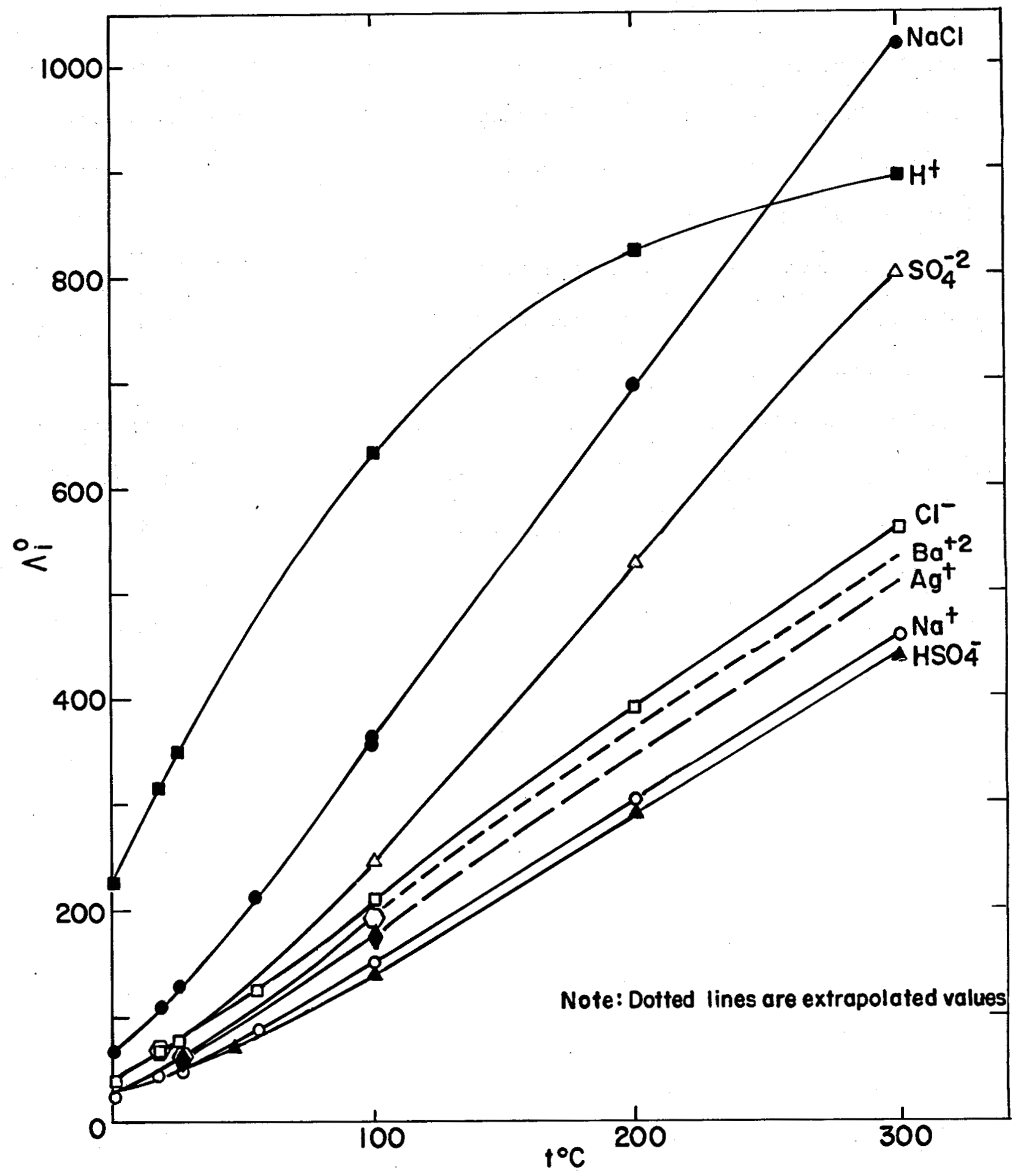

Figure 2. Temperature dependence of experimental limiting ionic conductances $\Lambda_{i}^{Q}$ as a function of temperature. 
Table 1. Estimates and data for $\Lambda_{i}^{0}$ at various temperatures.

\begin{tabular}{|c|c|c|c|c|c|c|c|c|}
\hline \multirow[b]{2}{*}{ Ion } & \multicolumn{7}{|c|}{$\Lambda_{i}^{0}, \mathrm{~cm}^{2} /$ (ohm equiv) } & \multirow[b]{2}{*}{$300^{\circ} \mathrm{C}$} \\
\hline & $0^{\circ} \mathrm{C}$ & $25^{\circ} \mathrm{C}$ & $50^{\circ} \mathrm{C}$ & $100^{\circ} \mathrm{C}$ & $150^{\circ} \mathrm{C}$ & $200^{\circ} \mathrm{C}$ & $250^{\circ} \mathrm{C}$ & \\
\hline \multicolumn{9}{|c|}{ Experimental Data } \\
\hline $\mathrm{H}^{+}$ & 225 & 350 & 463 & 634 & 752 & 824 & 865 & 894 \\
\hline $\mathrm{Na}^{+}$ & 26.5 & 50.1 & 80 & 151 & 226 & 304 & 382 & 459 \\
\hline $\mathrm{Cl}^{-}$ & 41.0 & 76.4 & 117 & 211 & 303 & 391 & 478 & 561 \\
\hline $\mathrm{HSO}_{4}^{-}$ & -- & 51.2 & 75 & 140 & 212 & 290 & 367 & 440 \\
\hline $\mathrm{So}_{4}^{-2}$ & 41 & 80 & 127 & 246 & 378 & 525 & 672 & 800 \\
\hline \multicolumn{9}{|c|}{ Ions from Geothermal Brines } \\
\hline $\mathrm{Ag}^{+}$ & 33.1 & 61.9 & 95 & 175 & 263 & 348 & 427 & 506 \\
\hline $\mathrm{Ba}^{+2}$ & 34.0 & 63.6 & 101 & 195 & 286 & 372 & 452 & 530 \\
\hline $\mathrm{zn}^{+2}$ & 28 & 52.8 & 84 & 159 & 237 & 319 & 401 & 482 \\
\hline $\mathrm{Cu}^{+2}$ & 29 & 53.6 & 85 & 163 & 241 & 319 & 393 & 466 \\
\hline $\mathrm{Fe}^{+2}$ & 30 & 55 & 87 & 167 & 247 & 327 & 403 & 478 \\
\hline $\mathrm{Pb}^{+2}$ & 38 & 69.5 & 109 & 203 & 294 & 382 & 465 & 546 \\
\hline \multicolumn{9}{|c|}{ Waste Isolation Ions } \\
\hline $\mathrm{Cs}^{+}$ & 44 & 77.2 & 116 & 210 & 303 & 390 & 478 & 561 \\
\hline$T^{+}$ & 225 & 350 & 463 & 634 & 752 & 824 & 865 & 894 \\
\hline$s r^{+2}$ & 31 & 59.4 & 95 & 180 & 266 & 346 & 420 & 493 \\
\hline $\mathrm{Ra}^{+2}$ & 35 & 65 & 103 & 200 & 292 & 380 & 461 & 541 \\
\hline $\mathrm{Ce}^{+3}$ & 37 & 70 & 111 & 214 & 314 & 408 & 496 & 581 \\
\hline $\mathrm{Pu}^{+3}$ & 34 & 64 & 101 & 195 & 286 & 372 & 452 & 530 \\
\hline $\mathbf{I}^{-}$ & 41.4 & 76.8 & 117 & 210 & 303 & 391 & 478 & 561 \\
\hline $\mathrm{TCO}_{4}^{-}$ & -- & 55 & 81 & 150 & 228 & 312 & 395 & 473 \\
\hline
\end{tabular}


Nigrini ${ }^{10}$ also linearly correlated $\Lambda_{i}^{0}$ up to $300^{\circ} \mathrm{C}$ in terms of $\Lambda_{i}^{0}$ at $25^{\circ} \mathrm{C}$. Linear coefficients are given at each of several temperatures for $+1,+2,+3$ cations, and for halogens, monovalent oxyanions, and divalent oxyanions. Because of limited data, few anions could be treated. The difference between $\Lambda_{i}^{0}$ values from his and our temperature correlations are 68 or less.

ESTIMATES OF TRACER $D_{i}^{0}$ AT INFINITE DILUTION

Table 2 contains the results of using the $\Lambda_{i}^{0}$ from Table 1 in Eqs. (8) or (9). Because of the $T$ factor in Eqs. (8) and (9), the tracer diffusion coefficient goes up faster with $T$ than does $\Lambda_{i}^{0}$. Moreover, because of the valence factor $z$ in the denominator, higher valence cations typically have smaller $D_{i}^{0}$ than univalent ions.

At the bottom of Table 2 are the average $D_{i}^{0}$, excluding $\mathrm{H}^{+}$and $\mathbf{T}^{+}$. A rough rule of thumb, good to about a factor of 2 is that the tracer diffusion coefficients of ions other than $\mathrm{H}^{+}, \mathrm{T}^{+}$, and $\mathrm{OH}^{-}$are: $10^{-5} \mathrm{~cm}^{2} / \mathrm{s}$ at $25^{\circ} \mathrm{C}$, half the $25^{\circ}$ value at $0^{\circ}$, double at $50^{\circ}, 4$ times at $100^{\circ}, 7$ times at $150^{\circ}, 10$ times at $200^{\circ}, 15$ times at $250^{\circ}$, and 20 times at $300^{\circ}$. The average

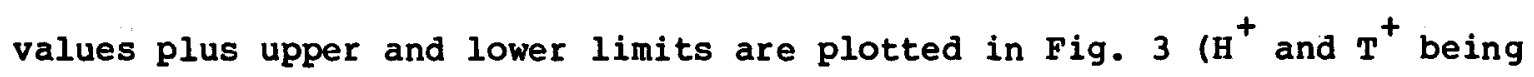
excluded). Figure 3 is thus suitable for crude estimates. Campbell ${ }^{11}$ has noted that the average values in $\mathrm{cm}^{2} / \mathrm{s}$ from Table 2 between 25 and $300^{\circ} \mathrm{C}$ can be described quite well by the equation

$D_{i \text { ave }}^{0}=4.205 \times 10^{-3} \exp (-1746 / T)$

The calculated value at $0^{\circ} \mathrm{C}$, however, is $40 \%$ too high, but still within the factor of 2 . 
Table 2. Estimates of tracer $D_{i}^{0}$ at various temperatures at infinite dilution.

\begin{tabular}{|c|c|c|c|c|c|c|c|c|}
\hline \multirow[b]{2}{*}{ Ion } & \multicolumn{5}{|c|}{$10^{5} \mathrm{D}_{\mathrm{i}}^{0}, \mathrm{~cm}^{2} / \mathrm{s}$} & \multirow[b]{2}{*}{$200^{\circ} \mathrm{C}$} & \multirow[b]{2}{*}{$250^{\circ} \mathrm{C}$} & \multirow[b]{2}{*}{$300^{\circ} \mathrm{C}$} \\
\hline & $0^{\circ} \mathrm{C}$ & $25^{\circ} \mathrm{C}$ & $50^{\circ} \mathrm{C}$ & $100^{\circ} \mathrm{C}$ & $150^{\circ} \mathrm{C}$ & & & \\
\hline \multicolumn{9}{|c|}{ Experimental Data } \\
\hline $\mathrm{H}^{+}$ & 5.5 & 9.3 & 13.4 & 21.1 & 28.4 & 34.8 & 40.4 & 45.8 \\
\hline $\mathrm{Na}^{+}$ & 0.65 & 1.3 & 2.3 & 5.0 & 8.5 & 12.8 & 17.8 & 23.5 \\
\hline $\mathrm{Cl}^{-}$ & 1.0 & 2.0 & 3.4 & 7.0 & 11.4 & 16.5 & 22.3 & 28.7 \\
\hline $\mathrm{HSO}_{4}^{-}$ & - & 1.4 & 2.2 & 4.7 & 8.0 & 12.3 & 17.1 & 22.5 \\
\hline $\mathrm{SO}_{4}^{-2}$ & 0.50 & 1.06 & 1.8 & 4.1 & 7.1 & 11.1 & 15.7 & 20.5 \\
\hline \multicolumn{9}{|c|}{ Ions from Geothermal Brines } \\
\hline $\mathrm{Ag}^{+}$ & 0.81 & 1.6 & 2.7 & 5.8 & 9.9 & 14.7 & 19.9 & 25.9 \\
\hline $\mathrm{Ba}^{+2}$ & 0.41 & 0.85 & 1.5 & 3.2 & 5.4 & 7.9 & 10.6 & 13.6 \\
\hline $\mathrm{zn}^{+2}$ & 0.34 & 0.70 & 1.2 & 2.6 & 4.5 & 6.7 & 9.4 & 12.3 \\
\hline $\mathrm{Cu}^{+2}$ & 0.35 & 0.71 & 1.2 & 2.7 & 4.6 & 6.7 & 9.2 & 11.9 \\
\hline $\mathrm{Fe}^{+2}$ & 0.37 & 0.73 & 1.3 & 2.8 & 4.7 & 6.9 & 9.4 & 12.2 \\
\hline $\mathrm{Pb}^{+2}$ & 0.46 & 0.93 & 1.6 & 3.4 & 5.6 & 8.1 & 10.9 & 14.0 \\
\hline \multicolumn{9}{|c|}{ Waste Isolation Ions } \\
\hline $\mathrm{Cs}^{+}$ & 1.1 & 2.1 & 3.3 & 7.0 & 11.4 & 10.5 & 22.3 & 28.7 \\
\hline $\mathbf{T}^{+}$ & 5.5 & 9.3 & 13.4 & 21.1 & 28.4 & 34.8 & 40.4 & 45.8 \\
\hline $\mathrm{sr}^{+2}$ & 0.38 & 0.79 & 1.4 & 3.0 & 5.0 & 7.3 & 9.8 & 12.6 \\
\hline $\mathrm{Ra}^{+2}$ & 0.43 & 0.87 & 1.5 & 3.3 & 5.5 & 8.0 & 10.8 & 13.8 \\
\hline $\mathrm{Ce}^{+3}$ & 0.30 & 0.62 & 1.1 & 2.4 & 4.0 & 5.7 & 7.7 & 9.9 \\
\hline $\mathrm{Pu}^{+3}$ & 0.28 & 0.57 & 1.0 & 2.2 & 3.6 & 5.2 & 7.0 & 9.0 \\
\hline & 1.01 & 2.0 & 3.4 & 7.0 & 11.4 & 16.5 & 22.3 & 28.7 \\
\hline $\mathrm{TCO}_{4}^{-}$ & - & 1.5 & 2.3 & 5.0 & 8.6 & 13.2 & 18.5 & 24.2 \\
\hline Averagea & 0.50 & 1.2 & $2 \cdot 0$ & $4 \cdot 2$ & 7.0 & $10 \cdot 4$ & $14 \cdot 2$ & $18 \cdot 4$ \\
\hline
\end{tabular}

a All but $\mathrm{H}^{+}, \mathrm{T}^{+}$. 


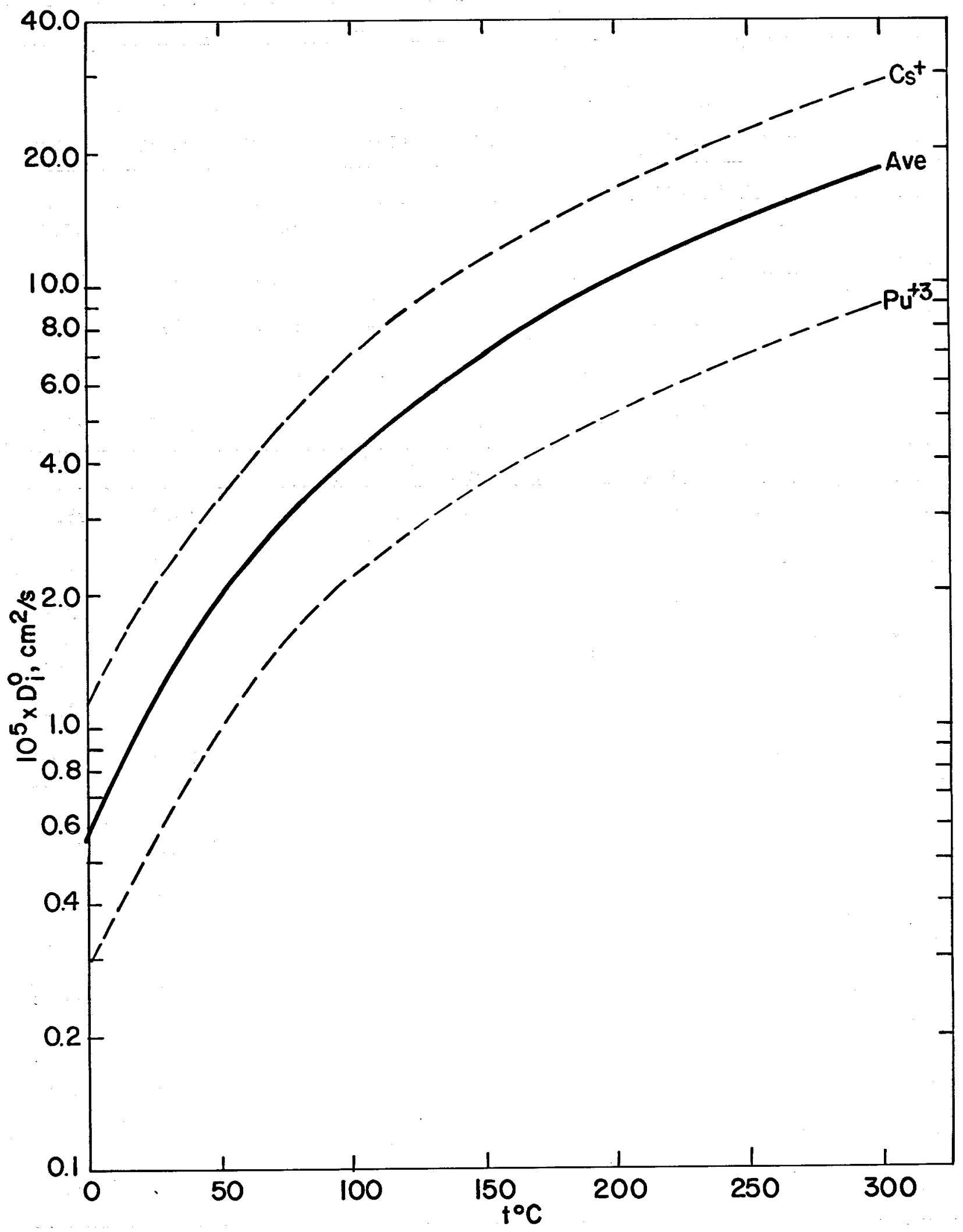

Figure 3. Temperature dependence of tracer diffusion coefficients (boundaries represent extremes of ions other than $\mathrm{H}^{+}, \mathrm{T}^{+}, \mathrm{OH}^{-}$).

12 
Again it is important to note that these infinite dilution values of $D_{i}^{0}$ are very approximate--except for the first group of ions for which $\Lambda_{i}^{0}$ was experimentally determined. Errors are greatest for ions whose values are based on analogy and/or extrapolation, and are of the order of 20-308.

Radioactive tracers can be used to measure $D_{1}$ at high dilution in diaphragm cells at higher temperatures to a few percent. Consequently it would be very desirable to measure some for a number of ions. This may ultimately be an easier way to get $\Lambda_{i}^{0}$ at high temperatures rather than limiting conductance and transference number measurements.

CONCENTRATION DEPENDENCE OF TRACER DIFFUSION COEFF ICIENTS

There are some data for tracer diffusion of one ion in its own solution for $+1,+2$, and -1 valence ions, often up to several mol $/ \mathrm{dm}^{3}$ (Refs. 12-20). There are also some data for univalent lons in 1-1 solutions of other salts. ${ }^{12-20}$ There do not appear to be any data for higher valence ions in other solutions.

From an examination of existing data, tracer $D_{1}$ generally decrease as the overall concentration increases. Some results ${ }^{11-18}$ for univalent ions in $\mathrm{NaCl}$ are shown in $\mathrm{Fig}, 4$, where $\mathrm{D}_{i} / \mathrm{D}_{i}^{0}$ at $25^{\circ} \mathrm{C}$ are plotted against the ionic strength $I$, where

$I=\frac{\sum c_{i} z_{i}^{2}}{2}$

where $c_{i}$ is now the concentration $\left(\mathrm{mol} / \mathrm{dm}^{3}\right.$ ) of ion $i$ and $z_{i}$ is its valence, and the sum is over all the ions (for a single $1-1$ salt, $I=c$; for a 2-1 salt, $I=3 c$; etc.). Figure 5 shows similar plots for +2 ions in their own chloride solutions at $25^{\circ} \mathrm{C} .12-20$ 


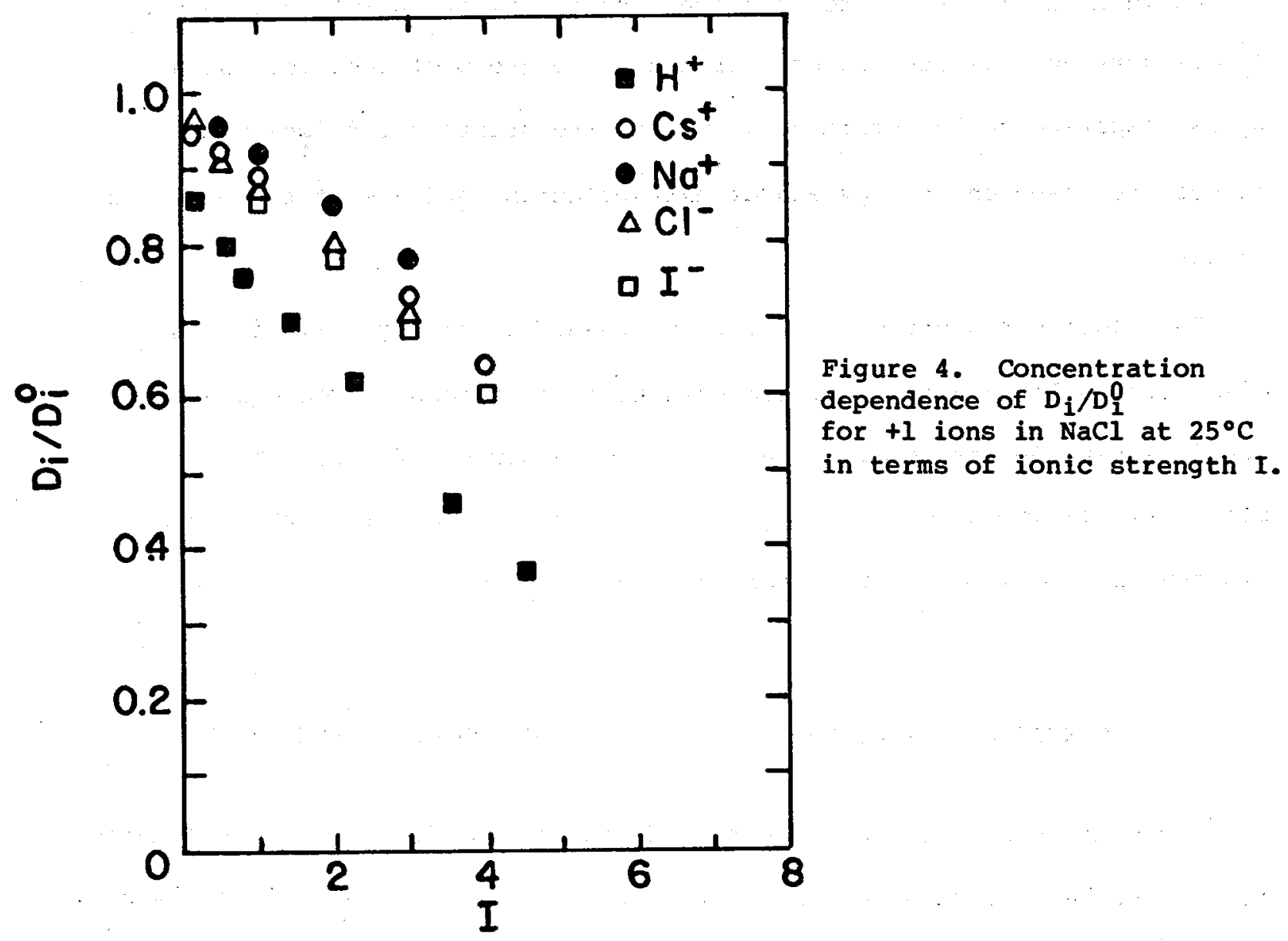

It will be seen from Fig. 4 that the decline of $D_{i} / D_{i}^{0}$ in $\mathrm{NaCl}$ solutions is much the same for all the ions, except that the $\mathrm{H}^{+}$ratio is somewhat lower everywhere. The similarity of $D_{i} / D_{i}^{0}$ for all ions in a given supporting electrolyte is generally true. ${ }^{20}$ Saturated $\mathrm{NaCl}$ is a good analogy to what would be expected from the nearly saturated Salton Sea geothermal brines and from solutions in bedded salt. Consequently for $\mathrm{T}^{+}$, $\mathrm{Cs}^{+}$, and $\mathrm{I}^{-}$, the tracer $\mathrm{D}_{i}^{0}$ in such $\mathrm{NaCl}$ brines should be about $1 / 3$ to $1 / 2$ of their values at infinite dilution.

Figure 5 shows that all the +2 ions have a similar decline in their own solutions. The ions $\mathrm{Mg}^{+2}, \mathrm{Ca}^{+2}, \mathrm{Ba}^{+2}$, and $\mathrm{Ni}^{+2}$ are all strong electrolytes, so that some similarity is not surprising. However, $\mathrm{Cd}^{+2}$ strongly complexes with $\mathrm{Cl}^{-}$in its own solutions, and the bulk of the complex might have been expected to slow down the trace ion. A possible 


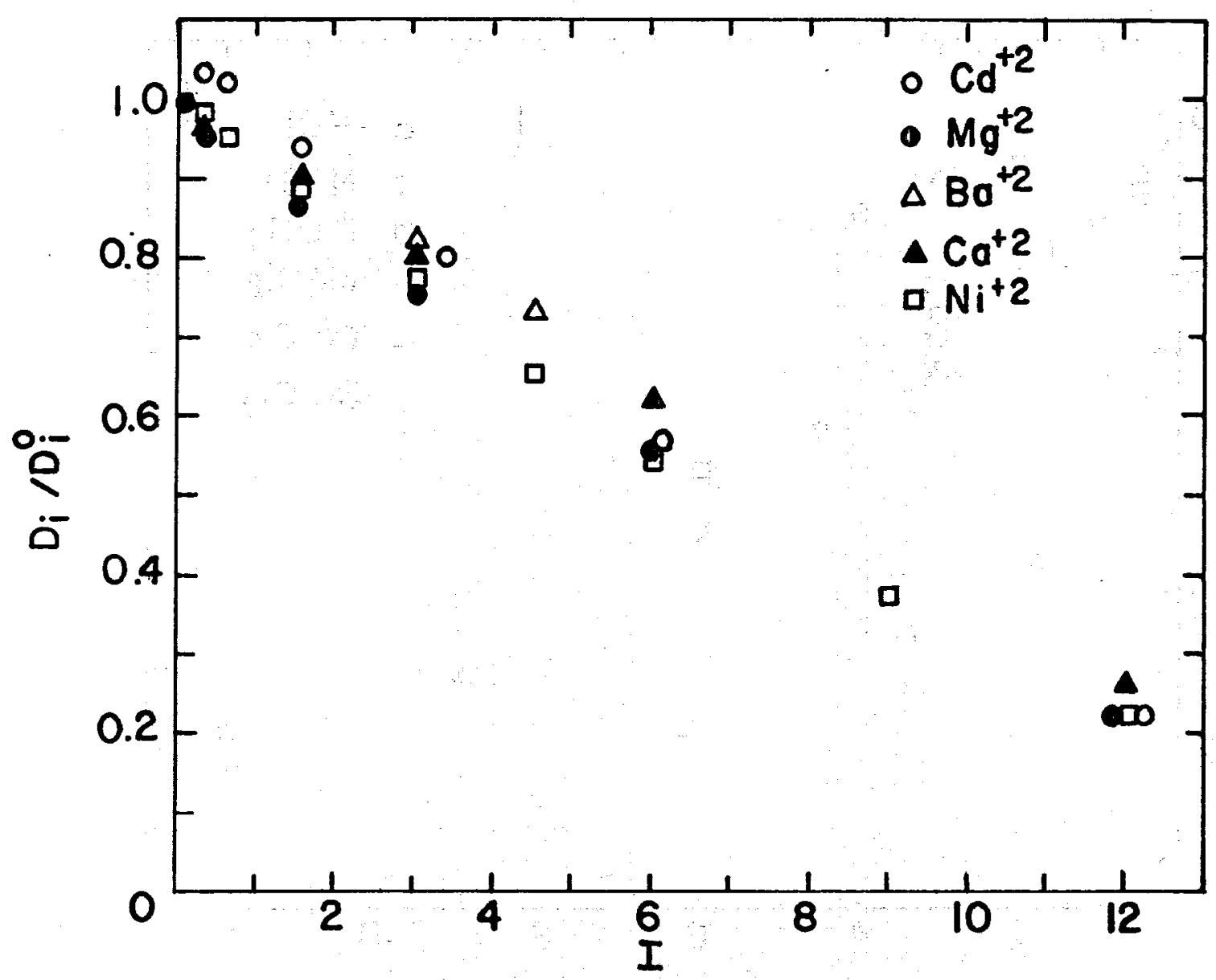

Figure 5. Concentration dependence of $D_{i} / D_{1}^{0}$ for +2 cations in their chlorides at $25^{\circ} \mathrm{C}$ in terms of ionic strength $\mathrm{I}$.

conclusion is that the complexed $\mathrm{Cd}^{+2}$ has about the same relative properties as the hydrated other +2 ions. On the other hand, the $D_{1} / D_{1}^{0}$ ratio for $\mathrm{Cl}^{-}$in $\mathrm{CdCl}_{2}$ is greatly affected by the complexing, whereas the ratio curves for $\mathrm{Cl}^{-}$in other +2 ion solutions are all much the same. It should also be noted that the ratios for $\mathrm{Cl}^{-}$in $\mathrm{KCl}$ solutions follow a curve different from ratios for $\mathrm{Cl}^{-}$in $\mathrm{NaCl}$ solutions. These $25^{\circ} \mathrm{C}$ results are shown in Fig. 6.

The only multicomponent system for which tracer data are available is $\mathrm{NaCl}-\mathrm{KCl}-\mathrm{H}_{2} \mathrm{O}^{21,22}$ It is found that generally tracer $\mathrm{D}_{i}$ for $\mathrm{Na}^{+}$. $\mathrm{K}^{+}$, and $\mathrm{Cl}^{-}$fall in between their values in $\mathrm{NaCl}$ and $\mathrm{KCl}$ at the same 


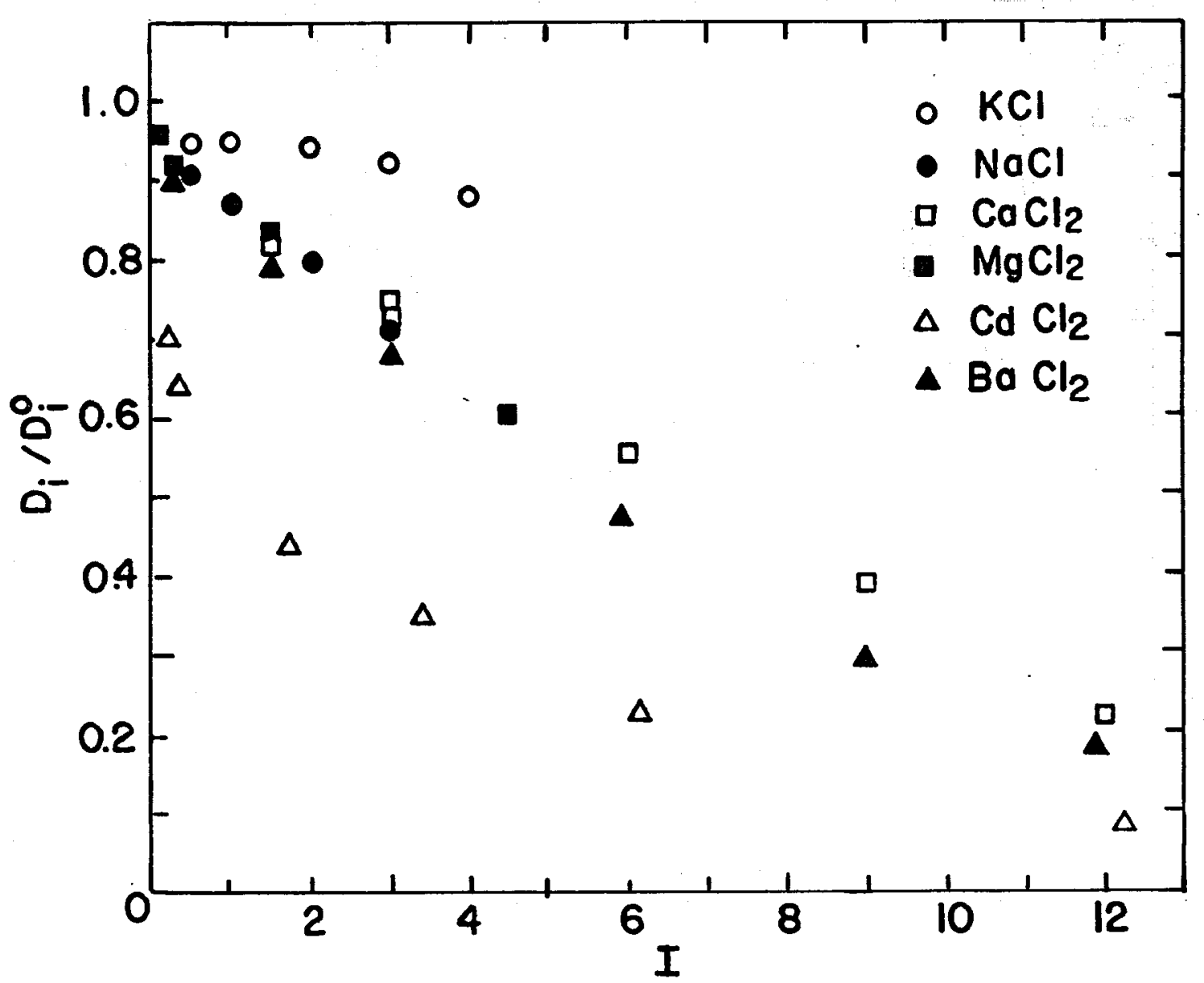

Figure 6. Concentration dependence of $\mathrm{D}_{\mathrm{i}} / \mathrm{D}_{\mathrm{i}}^{0}$ for $\mathrm{Cl}^{-}$in various chlorides at $25^{\circ} \mathrm{C}$ in terms of ionic strength ${ }^{i}$.

overall concentration. It is expected that this would hold true at least for other strong electrolyte mixtures at the same overall ionic strength.

Owing to inadequate data, it is difficult to offer any general estimation rule for tracer $D_{i}$ at high concentrations, other than $D_{i}$ decrease with increasing concentration. There appear to be so few data at other than $25^{\circ} \mathrm{C}$ that essentially nothing can be said. Perhaps to $200^{\circ} \mathrm{C}$, the decline in $\mathrm{D}_{i}$ with concentration may possibly be similar to the results at $25^{\circ} \mathrm{C}$. Thus, in bedded salt, an arbitrary choice of $D_{i} / D_{i}^{0}=0.5$ in $5 \mathrm{M} \mathrm{NaCl}$ will

probably be good to a factor of 2. Clearly it would be desirable to obtain experimental tracer data in $\mathrm{NaCl}$ for many more ions and at some higher temperatures. 
1. D. G. Miller, J. Phys. Chem. 71, 616 (1967).

2. P. J. Dunlop, B. J. Steel, and J. E. Lane, in "Physical Methods of Chemistry," A. Weissburger and B. W. Rossiter, Eds.., Vol. 1, Part IV, Chapt. IV, p. 205 (John Wiley, New York, 1972).

3. H. Kim, R. Deonier, and G. M. Reinfelds, J. Solution Chem. 3, 445 (1974).

4. D. G. Miller, J. Phys. Chem. 71, 3588 (1967).

5. R. C. Reid, J. M. Prausnitz, and T. R. Sherwood, "The Properties of Gases and Liquids," 3rd ed. (McGraw-Hill, New York, 1977), Chapter 11.

6. R. A. Robinson and R. H. Stokes, "Electrolyte Solutions," 2nd ed.., revised (Butterworths, London, 1965), pp. 463, 465.

7. H. S. Harned and B. B. Owen, "The Physical Chemistry of Electrolytic Solutions," 3rd ed. (Reinhold Publishing Corp., New York, 1958), p. 231.

8. A. S. Quist and W. L. Marshall, J. Phys. Chem. 69, 2984 (1965).

9. A. S. Quist and W. L. Marshall, J. Phys. Chem. 72, 684 (1968).

10. A. Nigrini, Am. Jour. Sci. 269, 65 (1970).

11. J. H. Campbell, Lawrence Livermore National Laboratory, Livermore, Calif., private communication, August 30, 1982.

12. R. Mills, Rev. Pure App. Chem. 11, 78 (1961).

13. H. G. Hertz, M. Holtz, and R. Mills, J. Chim. Phys. 71, 1355 (1974).

14. H. G. Hertz and R. Mills, J. Chim. Phys. 73, 499 (1976).

15. K. R. Harris, H. G. Hertz, and R. Mills, J. Chim. Phys. 75, 391 (1978).

16. H. G. Hertz and R. Mills, J. Phys. Chem. 82, 952 (1978).

17. H. G. Hertz, K. R. Harris, R. Mills, and L. A. Woolf, Ber. Bunsen Ges. Phys. Chem. 81, 664 (1977).

18. R. H. Stokes, S. Phang, and R. Mills, J. Solution Chem. 8, 489 (1979).

19. R. Mills, Australian National University, Canberra, private communication, May 22, 1981.

20. R. Mills, Australian National University, Canberra, private communication, March 23, 1982.

21. L. A. Woolf, J. Phys. Chem. B2, 959 (1978).

22. L. W. Barr, D. G. Miller, and R. Mills, J. solution Chem. 9 , 75 (1980). 